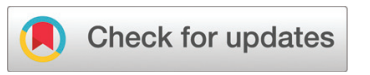

Cite this: Nanoscale, 2021, 13, 11478

\title{
Beneficial effects of cesium acetate in the sequential deposition method for perovskite solar cells $\dagger$
}

\author{
Byeong Jo Kim (D) and Gerrit Boschloo (D)*
}

\begin{abstract}
The cesium cation $\left(\mathrm{Cs}^{+}\right)$is widely used as a dopant for highly efficient and stable formamidinium lead trihalide perovskite $\left(\mathrm{FAPbX}_{3}, \mathrm{X}=\mathrm{I}, \mathrm{Br}, \mathrm{Cl}\right.$ ) solar cells. Herein, we introduce a small amount of cesium acetate (CsAc) that can effectively stabilize FAMAPb| ${ }_{3}$ under thermal- and light illumination-stress. We show that incorporated $\mathrm{Cs}^{+}$leads to relaxation of strain in the perovskite layer, and that $\mathrm{Ac}^{-}$forms a strong intermediate phase with $\mathrm{Pbl}_{2}$, which can help the intercalation of the $\mathrm{Pbl}_{2}$ film with $\mathrm{Cs}^{+}$and cation halide (FAl, $\mathrm{MAI}, \mathrm{MACl}$ ) in the sequential deposition process. The addition of CsAc reduces the trap density in the resulting perovskite layers and extends their carrier lifetime. The CsAc-modified perovskite solar cells show less hysteresis phenomena and enhanced operational and thermal stability in ambient conditions. Our findings provide insight into how dopants and synthesis precursors play an important role in efficient and stable perovskite solar cells.
\end{abstract}

Received 26th February 2021, Accepted 1st May 2021

DOI: $10.1039 / \mathrm{d} 1 \mathrm{nr} 01281 \mathrm{a}$ rsc.li/nanoscale lead triiodide $\left(\mathrm{FAPbI}_{3}\right)$, with a more ideal bandgap for a singlejunction solar cell of $1.5 \mathrm{eV},{ }^{12}$ using a similar method by replacing MA with FA, cannot be simply achieved. The larger ionic radius of $\mathrm{FA}^{+}(2.79 \AA)$ compared to $\mathrm{MA}^{+}(2.70 \AA)$ makes it more difficult to incorporate into the $\left[\mathrm{PbI}_{6}\right]^{4-}$ framework. ${ }^{13}$ Furthermore, $\mathrm{FAPbI}_{3}$ can easily convert to the yellow $\beta$-FAPbI ${ }_{3}$ non-perovskite phase from the $\alpha-\mathrm{FAPbI}_{3}$ black phase at RT. ${ }^{14,15}$ In order to obtain a stable $\alpha-\mathrm{FAPbI}_{3}$ black phase using sequential deposition, it is important to structurally engineer the metal halide layer for favorable phase transition from solid $\left(\mathrm{PbI}_{2}\right)$-liquid (FAI) to solid ( $\left.\mathrm{FAPbI}_{3}\right)$ and to engineer the precise composition of the perovskite layer to reduce the defect density.

The microstructure of the $\mathrm{PbI}_{2}$ film affects the interdiffusion of cation halide solution, leading to changes in morphology, nucleation sites, grain size, and fraction of remnant $\mathrm{PbI}_{2}$ of the final perovskite film..$^{8,16-18}$ Also, the lattice spacing of layered $\left[\mathrm{PbI}_{6}\right]^{4-}$ in the $\mathrm{PbI}_{2}$ layer affects volume expansion or shrinkage during the reaction and phase transition (annealing step), leading to defects and lattice strain in the perovskite layer. ${ }^{5,19}$ A solvent engineering method is commonly used to make more porous $\mathrm{PbI}_{2}$ layers and to extend lattice spacing. ${ }^{20,21}$ Various polar aprotic solvents, such as DMSO, NMP, HMPA, TBP, etc., are Lewis bases and form Lewis adducts with $\mathrm{PbI}_{2}$. After evaporation of the solvent through an annealing step, the morphology and porosity of $\mathrm{PbI}_{2}$ layers are controlled by the Lewis basicity of the solvents. Furthermore, any remaining Lewis base molecules in the $\mathrm{PbI}_{2}$ film after annealing affect the intercalation reaction. Remnant DMSO molecules act as spacers between layered $\left[\mathrm{PbI}_{6}\right]^{4-}$ to facilitate
Department of Chemistry-Ångström Laboratory, Physical Chemistry,

Uppsala University, Box 523, SE 75120 Uppsala, Sweden.

E-mail: gerrit.boschloo@kemi.uu.se

$\dagger$ Electronic supplementary information (ESI) available. See DOI: 10.1039/ d1nr01281a 
the interdiffusion of cation ions $\left(c f . \mathrm{FA}^{+}\right.$or $\left.\mathrm{MA}^{+}\right) .^{5,22}$ In addition, the remaining DMSO can form an amorphous intermediate phase $\left(\mathrm{PbI}_{2}\right.$-DMSO), which retards the crystallization of $\mathrm{PbI}_{2} \cdot{ }^{23}$ This approach helps the formation of $\alpha-\mathrm{FAPbI}_{3}$ with excellent initial performance and stability in dark-inert conditions, however, it does not contribute significantly to the operational stability of the resulting perovskite solar cell devices.

Therefore, small cation doping strategies have been investigated for $\mathrm{FAPbI}_{3}$ to enhance its stability. ${ }^{24-26}$ The Cs cation is widely used as a conventional dopant. In the sequential process, cesium halide ( $\mathrm{CsX}$, where $\mathrm{X}=\mathrm{I}, \mathrm{Br}, \mathrm{Cl}, \mathrm{F}$ ) is added to the $\mathrm{PbI}_{2}\left(1^{\text {st }}\right.$ step $)$ or mixed cation halide solution $\left(2^{\text {nd }}\right.$ step). ${ }^{27-31}$ However, adding CsX in the 1st-step is challenging as $\mathrm{CsX}$ in the $\mathrm{PbI}_{2}$ layer can form the non-perovskite $\delta$-phase $\mathrm{CsPbI}_{3},{ }^{32,33}$ which causes poor photovoltaic properties. Also, adding CsX in the $2^{\text {nd }}$ step is barely used due to limited solubility of cesium halide salt in 2-propanol (IPA), which is the commonly used solvent in the $2^{\text {nd }}$ step. Although the CsX doping method barely succeeds via the sequential process, it is found that a $\mathrm{Cs}^{+}$dopant in $\mathrm{PbI}_{2}$ layers is incorporated in the intermediate between $\mathrm{PbI}_{2}$ and $\mathrm{DMSO}$, affecting crystallization of $\mathrm{PbI}_{2}$. This change leads to enhanced thermal-, and phasestability of $\mathrm{Cs}: \mathrm{FAPbI}_{3}$. In other words, a CsX containing $\mathrm{PbI}_{2}$ layer not only supplies $\mathrm{Cs}^{+}$to perovskite, but it also has a significant influence on the resulting perovskite. One thing of interest is that the $\mathrm{CsCl}$ additive is more involved in formation of the perovskite ( $c f$. retarding crystallization, bigger grain size, and reduced defect site) compared to CsI, or CsBr additives. ${ }^{29}$ Generally, the $\mathrm{Cl}^{-}$ion plays a role in the growth mechanism of perovskite crystals.

Recently, CsAc was used in an antisolvent based one-step perovskite layer. ${ }^{34}$ The CsAc additive improved the efficiency and stability of $\mathrm{FA}_{0.85} \mathrm{MA}_{0.15} \mathrm{PbI}_{3}$ based solar cells. During the film formation process, strong interaction between $\mathrm{Ac}^{-}$and $\mathrm{Pb}^{2+}$ plays a significant role in the improved quality of the resulting perovskite films. Moreover, various previous reports have confirmed that $\mathrm{Ac}^{-}$(in the form of $\mathrm{PbAc}_{2}$, FAAc, MAAc) are engaged in the perovskite growth process, leading to larger grains, and reducing defects. ${ }^{35-37}$

Herein, we introduce CsAc into the $\mathrm{PbI}_{2}$ layer for the sequential deposition of efficient and stable $\mathrm{FAPbI}_{3}$ perovskite solar cells. CsAc acts both as the $\mathrm{Cs}^{+}$source and as a crystal growth enhancer in the process. CsAc is dissolved into the $\mathrm{PbI}_{2}-\mathrm{DMSO}-\mathrm{DMF}$ solution, which is spin coated and yields a CsAc containing $\left[\mathrm{PbI}_{6}\right]^{4-}$ layer as a framework for perovskite formation. Subsequently, we deposit a mixed cation halide salt (FAI : MAI : MACl) solution on the CsAc: $\mathrm{PbI}_{2}$ layer to form a narrow bandgap perovskite layer. We identify that $\mathrm{Cs}^{+}$and $\mathrm{Ac}^{-}$ are incorporated in the $\mathrm{PbI}_{2}$ layer, obtaining a change of morphology and giving an intermediate phase. CsAc addition to the $\mathrm{PbI}_{2}$ film is demonstrated to affect the optoelectrical properties and degree of lattice relaxation in the resultant perovskite layer. For instance, the CsAc additive is found to slightly narrow the optical bandgap and to reduce the density of trap sites in the perovskite film. Consequently, CsAc added perovs- kite solar cells achieved higher efficiency (21.26\%) and operational stability under 1-sun illumination (6\% loss of PCE after 70 minutes), compared to control perovskite solar cells (20.38\%, and $20 \%$ loss of PCE after 70 minutes). More interestingly, CsAc added perovskite solar cells fully recovered their absorbance spectrum after thermal stress test at $120{ }^{\circ} \mathrm{C}$ for $500 \mathrm{~min}$. These findings provide a new strategy to select the inorganic dopant source to make a sustainable perovskite material.

\section{Results and discussion}

To investigate how CsAc influences the performance of perovskite devices, we evaluated the performance of perovskite devices fabricated using $0,1,2$, and $3 \mathrm{~mol} \%$ of CsAc added to the $\mathrm{PbI}_{2}$ solution, and note the $x$ mol\% CsAc in perovskite films and devices by CsAc- $x(x=0,1,2$, and 3$)$ in the following. In Fig. 1a, we illustrate the fabrication step of CsAc-0 and CsAc- $x$ added perovskite layer and device architecture. The cross-sectional scanning electron microscopy (SEM) image for the $1 \mathrm{~mol} \%$ CsAc added perovskite device is shown in Fig. $1 \mathrm{~b}$ (see Fig. S1a, ESI $\dagger$ for cross-sectional SEM image of control device).

In the early stages of this study, we started with 5 mol\% of CsAc doping. Generally, this doping level showed optimum doping effects for perovskite devices in previous studies. ${ }^{38,39}$ However, a lower concentration of CsAc dopant gives more positive results in this work, as can be seen in Fig. S2, ESI and Table S1, ESI. $\dagger$ Fig. 1c represents the average power conversion efficiency (PCE) of forward and reverse scan direction of CsAc$x$ perovskite solar cell devices. The statistics of the other photovoltaics parameters is represented in Fig. S3, ESI. $\dagger$ The CsAc-1 devices have higher average PCE and a narrower distribution than CsAc-0 devices. The average PCE decreased when CsAc concentration was increased to 2 , and $3 \mathrm{~mol} \%$. This trend of PCE originates from the hysteresis phenomenon. We have split the statistics of average PCE into results from forward and reverse scans in Fig. S4, ESI. $\dagger$ The average PCE from reverse scans exhibited similar values of $21.16 \%, 21.54 \%, 20.89 \%$, and $21.12 \%$ for CsAc-0 to CsAc-3, respectively. However, in the forward scans, the trend was $18.74 \%, 20.19 \%, 18.55 \%$, and $18.10 \%$ from CsAc-0 to CsAc-3, respectively, displaying a big difference. The best devices, CsAc-0 and CsAc-1, demonstrated comparable reverse scanned PCE (21.84\% and $22.19 \%)$ and photovoltaics parameters, but they showed significant difference in open circuit voltage $\left(V_{\mathrm{oc}}\right)$ and fill factor $(\mathrm{FF})$ in the forward scan (Fig. 1d and Table S2, ESI†). In Fig. 1e, the integrated photocurrent density obtained from the incident photon-to-current conversion efficiency (IPCE) spectrum was $23.45 \mathrm{~mA} \mathrm{~cm}^{-2}$ and $24.27 \mathrm{~mA} \mathrm{~cm}^{-2}$ for CsAc-0 and CsAc-1 devices, respectively. The mismatch of current density between IPCE measurement and $J-V$ curve was around $1.7 \mathrm{~mA} \mathrm{~cm} \mathrm{~cm}^{-2}$ (92.5\%) and $1.2 \mathrm{~mA} \mathrm{~cm} \mathrm{~cm}^{-2}(95.3 \%)$ and is consistent with general $J_{\mathrm{sc}}$ mismatch in the perovskite field. ${ }^{40}$ Furthermore, we performed maximum power output tests under AM1.5G simulated sunlight in ambient air, Fig. 1f. The CsAc-1 device 
a

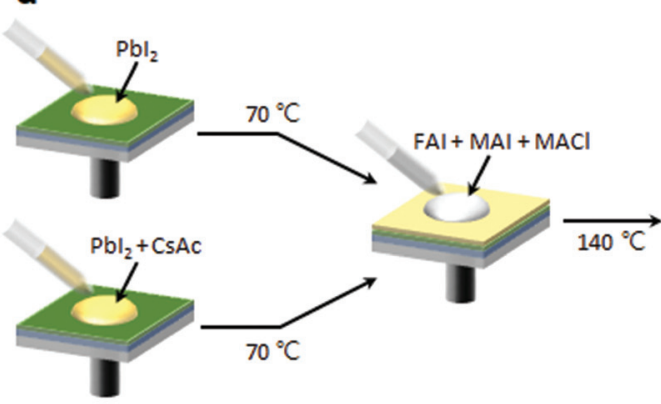

b

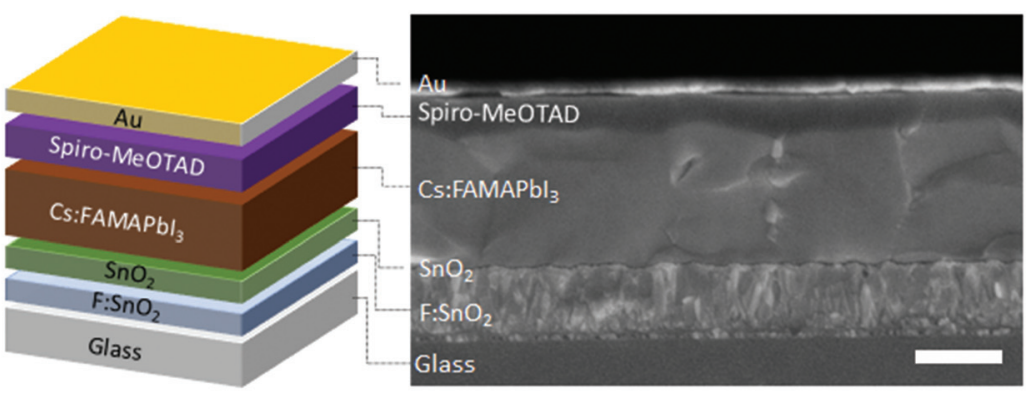

C

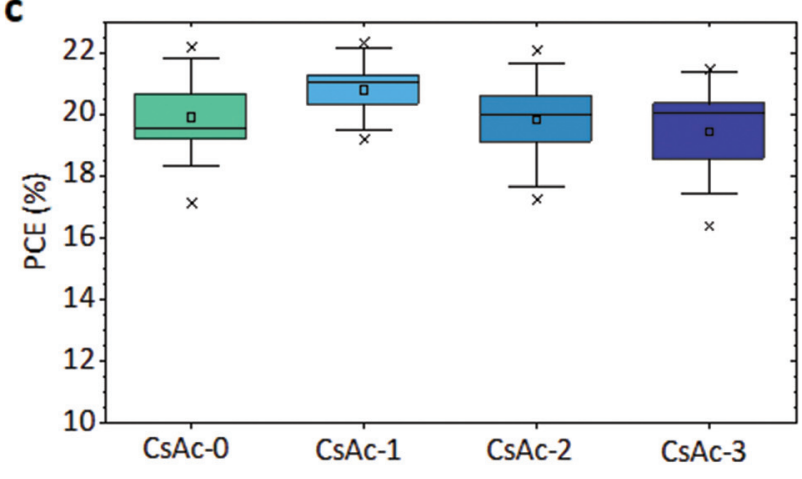

e

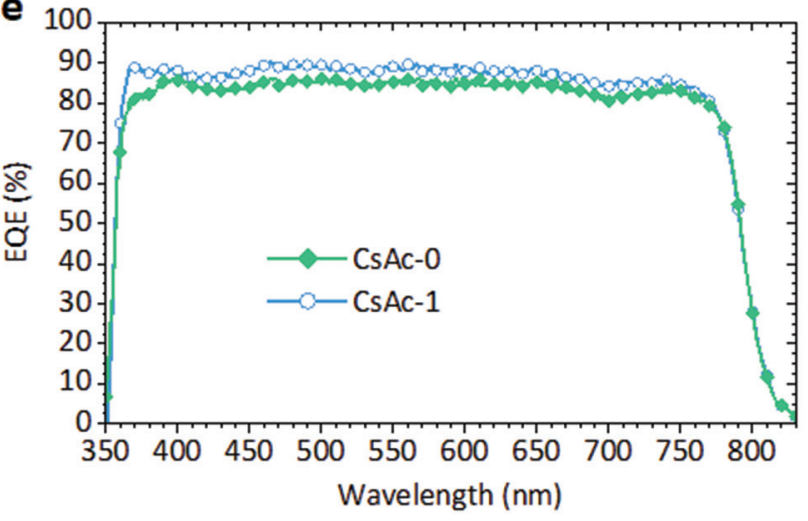

d

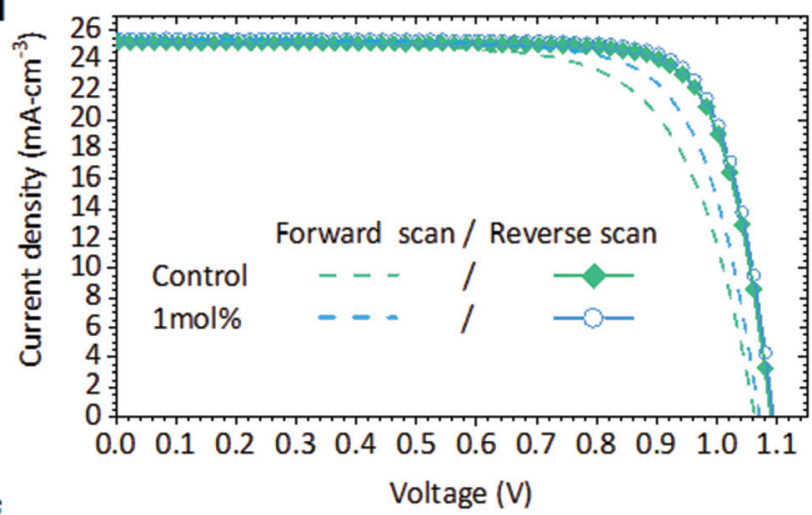

$\mathbf{f}$

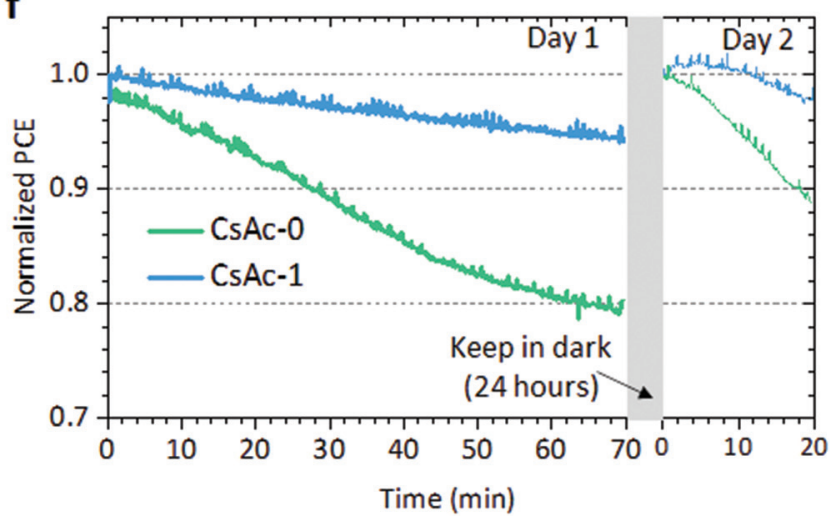

Fig. 1 Photovoltaics performance and operation stability. (a) Illustration of the fabrication process, architecture of CsAc added perovskite solar cell. (b) Cross-sectional SEM images of CsAc-1 solar cells. The scale bar is $500 \mathrm{~nm}$. (c) The statistics of average PCE values obtained for CsAc-0, $-1,-2$, and -3 (The boxes show the standard deviation, $n=16$; the whiskers represent the 10/90 percentile; the small squares denote the mean, the two horizon bars denote the $99 \%$ and $1 \%$ values, and the two diagonal crosses denote the highest and lowest values). (d) $J-V$ curves and (e) the EQE spectra of the best devices, CsAc- 0 and CsAc-1. (f) Maximum power point tracking of CsAc-0 and CsAc-1 solar cells under 1.5 AM simulated sunlight in ambient air.

showed enhanced operating stability. It kept $94.5 \%$ of its initial PCE after 70 minutes of continuous illumination, whereas the PCE of the CsAc-0 device dropped to $94.5 \%$ of its initial PCE already after 13 minutes, and it decreased to $80 \%$ after 70 minutes. We stored measured perovskite solar cells in the dark and $\mathrm{N}_{2}$ conditions for 24 hours to check the selfhealing characteristics of the perovskite materials. ${ }^{41-43}$ If deterioration of PCE originates from accumulation of ions and formation of vacancies at interfaces under light illumination, the PCE can recover completely. However, if the perovskite is decomposed by applied bias and light, the PCE will not recover. After 24 hours, CsAc-1 recovered PCE up to $98.5 \%$ of the initial PCE on day 1, while CsAc-0 recovered to $94.9 \%$ of the initial PCE. In the $2^{\text {nd }}$ measurement day, both solar cells degraded under continued PCE testing in a similar trend as day 1 . The photovoltaic parameters and $J-V$ curves, recorded every 10 minutes, are listed in Table S3, ESI and Fig. S5, ESI $†$ corresponding to Fig. $1 \mathrm{f}$.

To reveal the role of the CsAc dopant, we first examined the $\mathrm{PbI}_{2}$ layers with CsAc. We note the $x$ mol\% CsAc added $\mathrm{PbI}_{2}$ layer by $\mathrm{PbI}_{2}-x$ in the following. Firstly, we measured top-view SEM images (Fig. 2a-d) and X-ray diffraction (XRD) measurements (Fig. 2e) for $\mathrm{PbI}_{2}-0$ to $\mathrm{PbI}_{2}-3$. When the CsAc concentration is increased to $3 \mathrm{~mol} \%$, the morphology of 

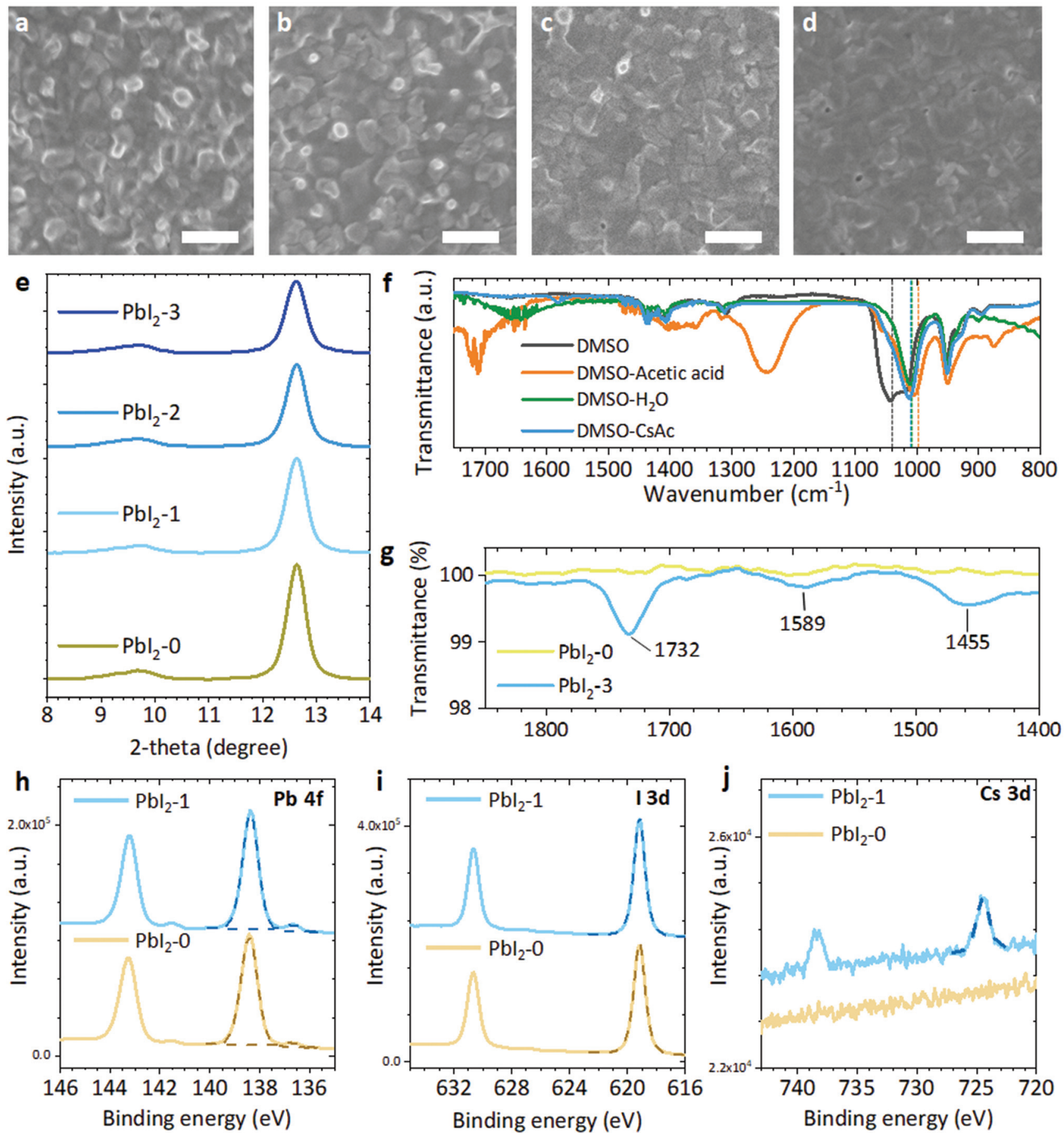

Fig. 2 Analysis of CsAc-added $\mathrm{Pbl}_{2}$ layer. (a-d) Plane FESEM images and (e) XRD patterns of $\mathrm{Pbl}_{2}-0,-1,-2$, and -3 . The scale bar is $1 \mu \mathrm{m}$. (f) FTIR spectra of solutions (DMSO, DMSO-acetic acid, DMSO- $\mathrm{H}_{2} \mathrm{O}$, and DMSO-CaAc) and $(\mathrm{g})$ films $\left(\mathrm{Pbl}_{2}-0\right.$, and $\left.\mathrm{Pbl}_{2}-3\right)$. Dot lines indicate the stretching bond of $\nu\left(\mathrm{S}=\mathrm{O}\right.$ ) in $\mathrm{DMSO}$. (h) $\mathrm{Pb} 4 \mathrm{f}$, (i) I $3 \mathrm{~d}$, (j) Cs $3 \mathrm{~d}$ xps spectra of $\mathrm{Pbl}_{2}-0$, and $\mathrm{Pbl}_{2}-3$ samples.

$\mathrm{PbI}_{2}-x$ films becomes smoother, but a few voids are visible. In the XRD, we can find some clue to explain this change of morphology. We found two peaks at $12.6^{\circ}$ and $9.6^{\circ}$ indicating the (100) planes of the $\mathrm{PbI}_{2}$ and the $\left(\mathrm{PbI}_{2}-\mathrm{DMSO}_{1}\right)$ phase, respectively. ${ }^{44}$ The relative peak intensity $\mathrm{PbI}_{2}-\mathrm{DMSO}_{1}\left(9.6^{\circ}\right) / \mathrm{PbI}_{2}$ $\left(12.6^{\circ}\right)$ is calculated and represented in Fig. S6, ESI. $\dagger$ As the addition of CsAc increased, the overall peak intensity decreased, and the relative ratio of $\mathrm{PbI}_{2}-\mathrm{DMSO}_{1}$ to $\mathrm{PbI}_{2}$ increased. It is well known that $\mathrm{PbI}_{2}$ films incorporated with DMSO has a more porous morphology and contains more amorphous phase compared to pure $\mathrm{PbI}_{2}$ films. So, the change of morphology is clear considering the increased peak of $\mathrm{PbI}_{2}-\mathrm{DMSO}_{1}$ phase.

To understand how CsAc can accelerate the formation of the $\mathrm{PbI}_{2}-\mathrm{DMSO}_{1}$ phase, we used Fourier-transform infrared 
spectroscopy (FTIR), see Fig. 2f. We prepared three pure solvents (DMSO, acetic acid and $\mathrm{H}_{2} \mathrm{O}$ ), three mixed solutions (DMSO and acetic acid, DMSO and $\mathrm{H}_{2} \mathrm{O}$, and DMSO and CsAc, prepared with 1:1 molar ratio) and heated all solutions overnight at $70{ }^{\circ} \mathrm{C}$ in the $\mathrm{Ar}$ atmosphere to obtain similar conditions for the fabrication step. In FTIR the peak at $1044 \mathrm{~cm}^{-1}$, indicates the stretching bond of $\nu(\mathrm{S}=\mathrm{O}),{ }^{45,46}$ in DMSO shifted to $1010 \mathrm{~cm}^{-1}$ and $1003 \mathrm{~cm}^{-1}$ in DMSO and $\mathrm{H}_{2} \mathrm{O}$ and DMSO and acetic acid, respectively. Also, the peak of $\nu(\mathrm{S}=\mathrm{O})$ in CsAc dissolved DMSO shifted to $1013 \mathrm{~cm}^{-1}$. The results indicate that the acetate ion in CsAc can assist to form the $\mathrm{PbI}_{2}-\mathrm{DMSO}_{1}$ phase. Recently, Kai Zhang et al. reported that strong hydrogen bonding of $\mathrm{H}_{2} \mathrm{O}$ with DMSO can reduce the activation energy to form the $\mathrm{PbI}_{2}-\mathrm{DMSO}_{1}$ phase in a similar way as acetic acid, and CsAc does in our results. ${ }^{45}$ The full range of FTIR results, including acetic acid and $\mathrm{H}_{2} \mathrm{O}$ are presented in Fig. S7, ESI. $\dagger$ FTIR spectra of $\mathrm{PbI}_{2}-x$ films are shown in Fig. 2g. The small stretching vibration of $\mathrm{C}=\mathrm{O}\left(1732 \mathrm{~cm}^{-1}\right)$ and $\mathrm{COO}^{-}$ $\left(1457 \mathrm{~cm}^{-1}\right.$ and $\left.1549 \mathrm{~cm}^{-1}\right)$ from the acetate ion were detected in $\mathrm{PbI}_{2}-3 .{ }^{47,48}$ However, the acetate ion related peaks are not monitored in $\mathrm{PbI}_{2}-1$ and $\mathrm{PbI}_{2}-2$ in Fig. S8, ESI. $\dagger$ It is thought to owe to the small amount of added acetate outside the detection range. We expect this interaction between Ac- and the intermediate phase of $\mathrm{PbI}_{2}-\mathrm{DMSO}_{1}$ may supply additional chemical space for intercalation reactions with organic halide solution.

From X-ray photoelectron spectroscopy (XPS), we identified the incorporation of $\mathrm{Cs}$ in the $\mathrm{PbI}_{2}$ films with added CsAc. For $\mathrm{Pb}, 138.4 \mathrm{eV}$ and $143.2 \mathrm{eV}$ binding energy are observed indicating the $\mathrm{Pb} 4 \mathrm{f}_{7 / 2}$ and $\mathrm{Pb} 4 \mathrm{f}_{5 / 2}$ core level, respectively (Fig. $2 \mathrm{~h}$ ). ${ }^{49}$ Metallic lead component $\left(\mathrm{Pb}^{0} 4 \mathrm{f}_{7 / 2}\right.$ and $\left.\mathrm{Pb}^{0} 4 \mathrm{f}_{5 / 2}\right)$ peaks appear at $136.7 \mathrm{eV}$ and $141.5 \mathrm{eV}$ : these appear because typical XPS analysis conditions (low pressure, röntgen radiation) can generate $\mathrm{Pb}^{0}$ in $\mathrm{PbI}_{2}$ components. ${ }^{50}$ For the I, I $3 \mathrm{~d}_{5 / 2}$ and $\mathrm{I} 3 \mathrm{~d}_{3 / 2}$ binding energy appear at $619.2 \mathrm{eV}$ and $630.7 \mathrm{eV}$, respectively (Fig. 2i). ${ }^{49}$ The Cs $3 \mathrm{~d}_{5 / 2}$ and Cs $3 \mathrm{~d}_{3 / 2}$ peaks are observed at $724.5 \mathrm{eV}$ and $738.4 \mathrm{eV}^{.49}$ In the XPS data, we could not find any significant differences except the presence of a Cs component in the $\mathrm{PbI}_{2}-1$ film. The full range of XPS measurement data, including the $\mathrm{PbI}_{2}-3$ film and more detailed XPS parameters of $\mathrm{Pb}$, I, Cs are listed in Fig. S9, ESI and Table S4. $\dagger$

To summarize this step, it is confirmed that $\mathrm{Cs}^{+}$and $\mathrm{Ac}^{-}$ was incorporated in the $\mathrm{PbI}_{2}$ layer, and that the added CsAc triggers the formation of a $\mathrm{PbI}_{2}-\mathrm{DMSO}_{1}$ phase, which is involved in the growth of perovskite.

In the two-step deposition of the perovskite layer, the nature of the $\mathrm{PbI}_{2}$ layer significantly affects the final perovskite film. Therefore, $\mathrm{PbI}_{2}-0$ to $\mathrm{PbI}_{2}-3$, which have different morphology, crystallinity, composition and $\mathrm{PbI}_{2}-\mathrm{DMSO}_{1}$ intermediate phases, lead to the formation of distinctively different perovskite films. A clear change of morphology between CsAc-0 and CsAc-3 can be seen in Fig. 3a-d. The SEM images indicate that the grain size of CsAc-3 suddenly increases compared to CsAc-0, -1 , and -2. Also, bright white areas, indicating surface remnant $\mathrm{PbI}_{2}$ components, ${ }^{51}$ gradually disappear by further increasing the CsAc concentration. However, contrary to expec- tations, CsAc-1 and CsAc-3 films had higher crystalline $\mathrm{PbI}_{2}$ components (at $12.6^{\circ}$ ) compared to CsAc- 0 in XRD analysis (Fig. 3e). Relative peak intensities of $\left[\mathrm{PbI}_{2}\right.$ at $\left.12.6^{\circ}\right] /\left[\alpha-\mathrm{FAPbI}_{3}\right.$ at $\left.14.0^{\circ}\right]$ are $0.57,0.82$ and 0.93 for CsAc-0, CsAc-1 and CsAc-3, respectively. The higher degree of remnant $\mathrm{PbI}_{2}$ is commonly observed in perovskite layers prepared using a 2-step method. Our expectation was that less $\mathrm{PbI}_{2}$ would be detected in CsAc-3 through the SEM result, but it was interesting that the higher intensity of crystalline $\mathrm{PbI}_{2}$ appeared in the CsAc-3 films. To analyze the surface distribution of the $\mathrm{PbI}_{2}$ and perovskite phase, we performed grazing incident XRD analysis using an incident beam of $1^{\circ}$ for CsAc-0 and CsAc-3. As seen in Fig. S10, $\mathrm{ESI}, \uparrow$ the relative peak intensities of $\left[\mathrm{PbI}_{2}\right.$ at $\left.12.6^{\circ}\right] /\left[\alpha-\mathrm{FAPbI}_{3}\right.$ at $14.0^{\circ}$ ] changed to 1.38 and 0.94 for CsAc-0 and CsAc-3. This indicates that CsAc-0 has more $\mathrm{PbI}_{2}$ on the upper part of the film than in the bulk, while a small amount of CsAc can induce well-distributed remnant $\mathrm{PbI}_{2}$ in bulk perovskite films. We can explain this difference in perovskite layers by the effects of CsAc contained in $\mathrm{PbI}_{2}$. As mentioned above, $\mathrm{Cs}^{+}$ makes the intermediate phase $\mathrm{PbI}_{2}-\mathrm{DMSO}_{1}$ stronger, and $\mathrm{Ac}^{-}$ can retard formation and growth of the perovskite. Moreover, we confirmed that $\mathrm{Ac}^{-}$also made the intermediate phase more stable. Therefore, the excessive CsAc rather hinders the process of $\mathrm{PbI}_{2}-\mathrm{DMSO}_{1}$ conversion to $\mathrm{PbI}_{2}$-organic cations, thereby inhibiting the formation of a perovskite thin film. Owing to the slow interdiffusion process and the slow film formation process, CsAc-3 has a relatively large grain and uniform $\mathrm{PbI}_{2}$ distribution, but the relative amount of $\mathrm{PbI}_{2}$ in the entire film increases. The obvious identified $\mathrm{Ac}^{-}$in $\mathrm{PbI}-3$ (Fig. 2g) made the clearly different morphology in the CsAc-3 (Fig. 3d) compared to others in this manner.

Also, we found a (111) plane and (002) plane shift toward higher diffraction angles in CsAc-1 and CsAc-3. This means the smaller radius of $\mathrm{Cs}^{+}(1.81 \AA)$ is smaller than FA $(2.79 \AA)$, and induces shrinkage of the lattice spacing by Bragg's law $\left(d_{h l k}=n \lambda / 2 \sin \theta\right)$. There are many studies showing that phase, operating, and thermal stability of perovskite devices can be enhanced through partial substitution of the $\mathrm{FA}^{+}$cation to relatively small A site cations. ${ }^{52,53}$ This lattice change allows the perovskite to respond to more flexible operating condition and thermodynamic changes. We confirmed that the CsAc-1 device showed operating stability comparable to CsAc-0 in Fig. 1f. To further understand the relationship between incorporated $\mathrm{Cs}^{+}$and lattice changes, a Williamson-Hall plot (Fig. S11 and Table S5, ESI $\dagger$ ) was analyzed to estimate the lattice strain in CsAc- $0,-1$, and -3 . The slope of the plot indicates the relative strain component, and the intercept gives the relative particle size. The relative lattice strain/crystallite size has been calculated as $4.31 \times 10^{-4} / 0.00573,3.60 \times 10^{-4} /$ 0.00575 , and $3.28 \times 10^{-4} / 0.00582$ for CsAc- $0,-1$, and -3 , respectively. The values correspond to the shift of the XRD peak, images of SEM and expected effect by small $\mathrm{Cs}^{+}$cation. In addition, we confirm the thermodynamic stability of CsAc-1 compared to CsAc-0 in Fig. 4.

We carried out photoluminescence (PL) measurements to investigate the optoelectrical properties resulting from the 

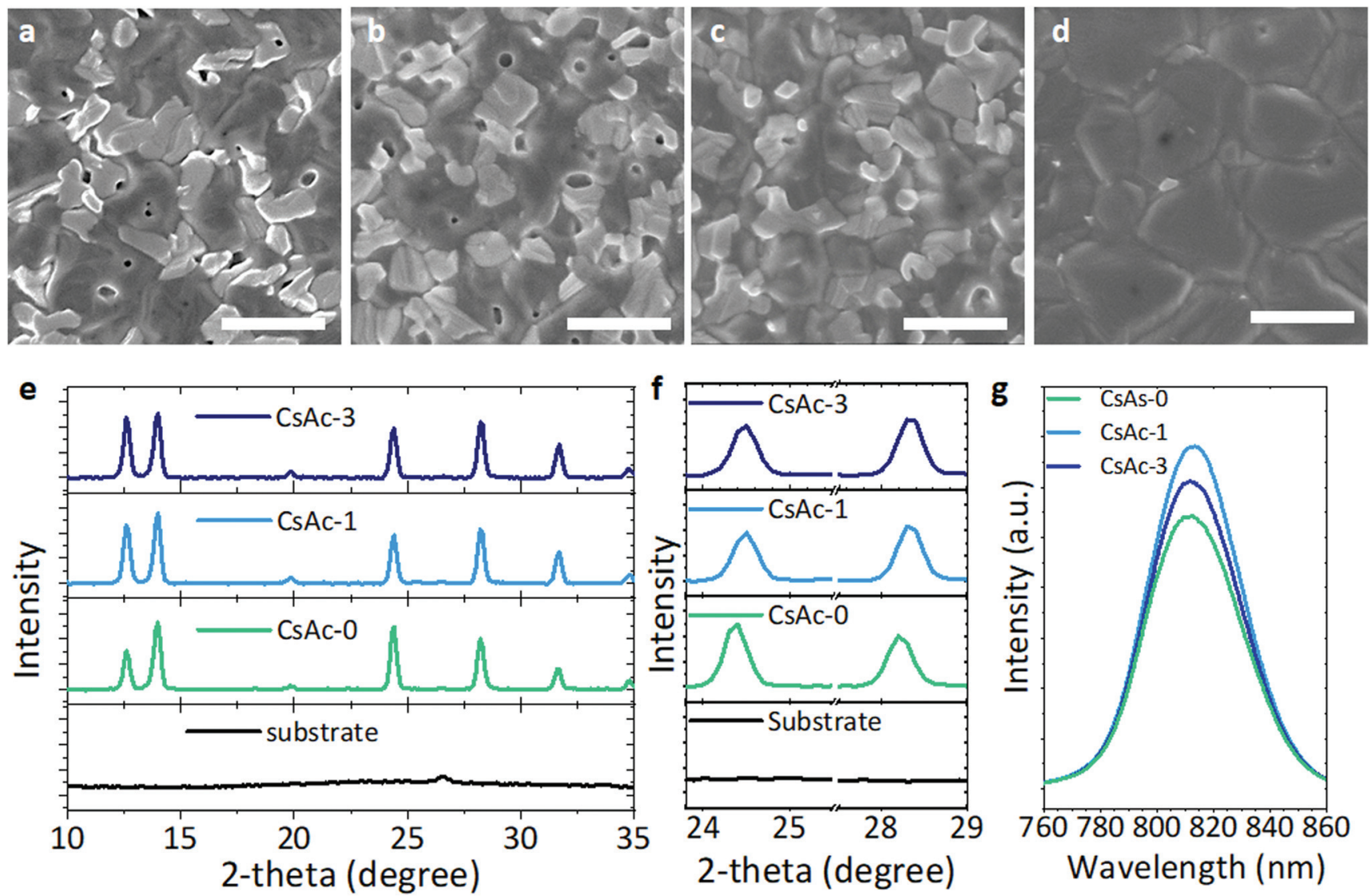

Fig. 3 Analysis of resultant perovskite films with or without CsAc. (a-d) Planar FESEM images of CsAc-0, $-1,-2$, and -3 . The scale bar is $1 \mu$ m. (e and f) X-ray diffraction patterns of CsAc-0, -1, -3, and substrate. (g) Steady-state photoluminescence (PL) spectra of CsAc-0, -1 , and -3 films on glass substrate.

addition of CsAc. For the photoluminescence analysis, we coated a thin PMMA layer on the glass/CsAc- $x$ sample to minimize interference with the atmosphere. The steady state PL intensity of CsAc-1 is higher than that of CsAc-0 and CsAc-3 films in Fig. 3g. It indicates that CsAc-1 perovskite films have less non-radiative recombination. The CsAc-1 shows a slightly red-shifted emission PL peak $(813 \mathrm{~nm})$ compared to CsAc-0 film $(812 \mathrm{~nm})$. We assume that the red shift of PL is due to a slight crystal structure changing by incorporating smaller $\mathrm{Cs}^{+}$ions into perovskite grains. In general, band structure is dominated by orbitals of I and $\mathrm{Pb}$. When changing the $\mathrm{A}$ site ion in $\mathrm{AMX}_{3}$ perovskite, electronic effects resulting from the $\mathrm{A}^{+}$ion incorporation are negligible or show varying trends. ${ }^{54,55}$ In the mixed cation perovskite system, orientation or distribution of cations has a greater effect on the band structure of perovskite materials. ${ }^{53,56}$ We have examined various changes in perovskite thin films by CsAc in $\mathrm{PbI}_{2}$. However, to confirm whether the change of perovskite $\left(\mathrm{PbI}_{2}\right.$ distribution, the lattice parameter, and the $\mathrm{PL}$ emission peak) finally result in a positive change in the perovskite solar cells, we conducted additional analysis.

The light intensity dependence of the photovoltaics parameters can give insight into the dominant recombination mechanism. We plotted the logarithm of $J_{\text {sc }}$ and light intensity in Fig. S12, ESI. $\dagger$ CsAc-0 and CsAc-1 show a linear increase which has a slope of 0.98 close to 1 , indicating that, under short-circuit conditions, most of the photogenerated charge carriers are extracted to an external circuit prior to recombination in the interface or bulk perovskite film. ${ }^{57}$ In Fig. $4 \mathrm{~b}$, we extracted $V_{\text {oc }}$ using various light intensity levels from 1 Sun to 0.1 Sun. In the diode equation $V_{\text {oc }}$ is given by $\frac{n k T}{q} \ln \left(\frac{I}{I_{0}}+1\right)$, where $n$ is the ideality factor, $k$ the Boltzmann constant, $T$ temperature, $q$ charge of an electron, and $I_{0}$ the saturated dark current. When $J_{\mathrm{sc}}$ increases linearly with light intensity, the slope of $V_{\mathrm{oc}}$ and logarithm of light intensity is determined by $n$. When $n$ is close to 1 , bimolecular recombination of charge carriers is dominant, while an $n$ close to 2 indicates trapassisted recombination. The CsAc- 1 device yielded a lower $n$ value of 1.23 compared to that of CsAc-0 $(n=1.60)$, suggesting that CsAc addition suppresses trap-assisted recombination.

Time-resolved photoluminescence (TRPL) measurements were performed for quantitative comparison of charge recombination related to non-radiative recombination by trap sites in the perovskite layer in Fig. 4a. Very long-lived PL decay was found for both CsAc-0 and CsAc-1 under the conditions used. 
a
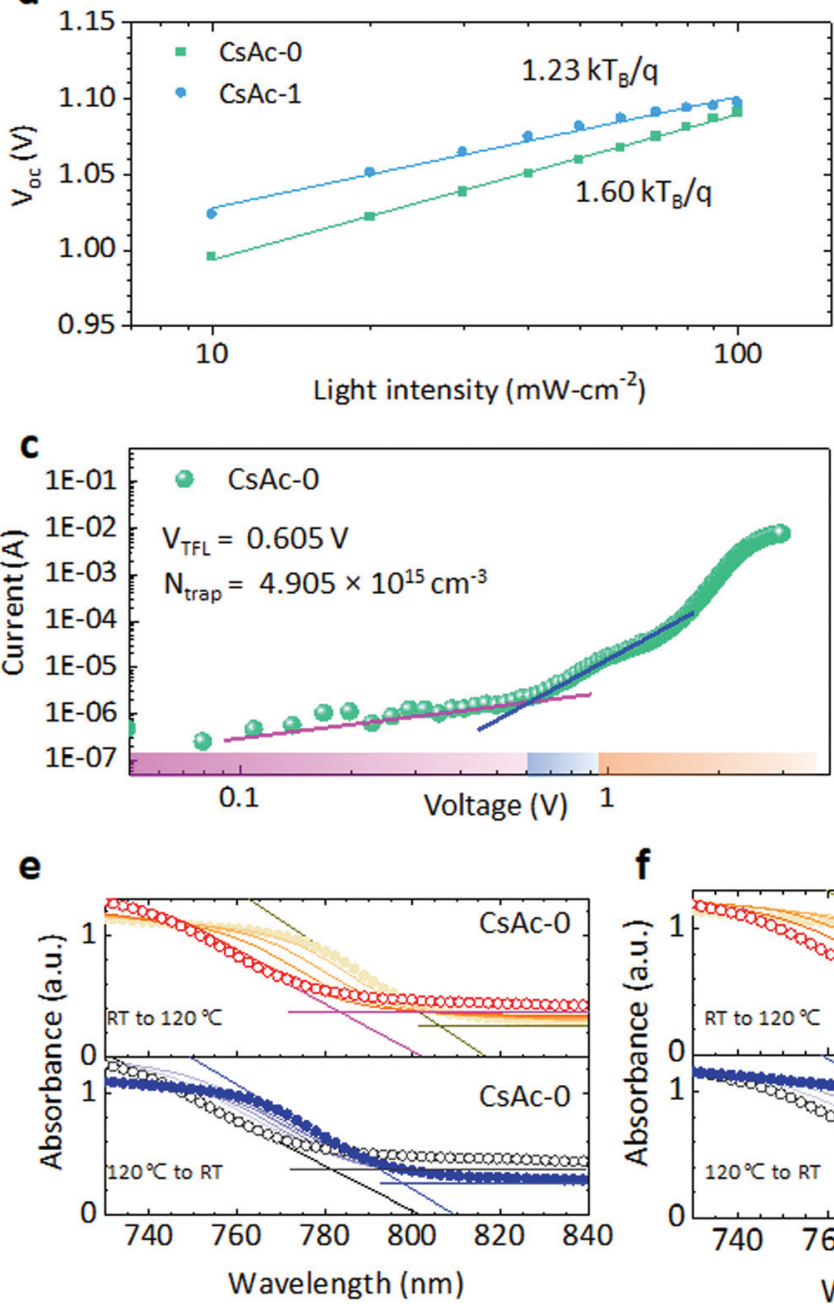

f b

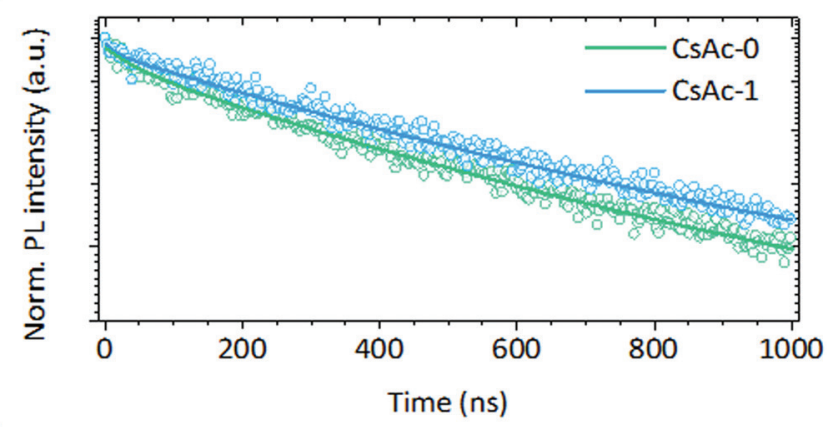

d

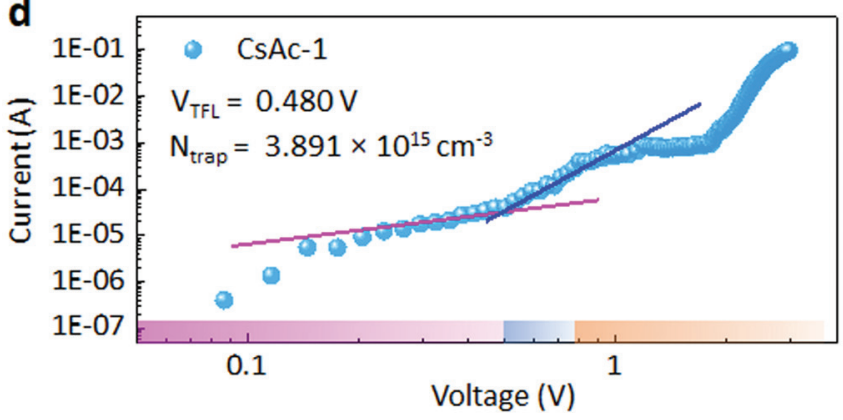

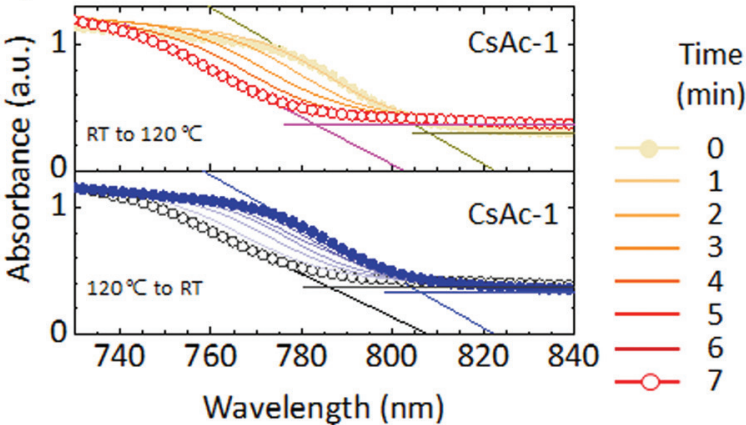

Time Temp. Time Temp.

$(\min ) \quad\left({ }^{\circ} \mathrm{C}\right) \quad(\min ) \quad\left({ }^{\circ} \mathrm{C}\right)$

$20 \multimap 500 \quad 120$

$30-50190$

$40-502 \quad 70$

$60-50360$

$-50450$

$-50543$

$100-506 \quad 35$

$110 \multimap 508 \quad 28$

Fig. 4 Defect analysis and degree of thermal-stress relaxation analysis of CsAc-0, and -1 perovskite films. (a) Light-intensity dependence of $V_{\text {oc }}$ (b) normalized time-resolved photoluminescence (TRPL) decay at $810 \mathrm{~nm}$ for glass/CsAc-0 or CsAc-1/PMMA samples. (c and d) Space charge limited current (SCLC) measurement of electron only devices based on the $\mathrm{FTO} / \mathrm{SnO}_{2} / \mathrm{CsAc}-0$ or $\mathrm{CsAc}-1 / \mathrm{PCBM} / \mathrm{Au}$ structure. Thermal stress test of (e) $\mathrm{CsAc}-0$ and (f) CsAc-1 using temperature controllable in situ UV-Vis spectroscopy. In the upper spectra (RT to $120^{\circ} \mathrm{C}$ ), temperature increased $20^{\circ} \mathrm{C}$ per minute. After 500 minutes, the temperature was spontaneously cooled down to RT and the temperature was recorded every 1 minute. UV-Vis spectra were recorded every 1 minute for 510 minutes.

The measured transients were fitted by a bi-exponential decay curve, PL intensity $=A_{1} \exp \left(-t / \tau_{1}\right)+A_{2} \exp \left(-t / \tau_{2}\right)$. The $\tau_{1}$ and $\tau_{2}$ denote the fast and slow decay time and are attributed to nonradiative recombination relating to interface (or surface) defects, and radiative recombination relating to bulk properties. $^{58,59}$ Average carrier lifetime $\left(\tau_{\text {ave }}\right)$ was calculated by $\sum A_{i} \tau_{i}^{2} / \sum A_{i} \tau_{i}^{2}(i=1,2)$. All fitted parameters and $\tau_{\text {ave }}$ of CsAc-0 and CsAc-1 are listed in Table S6, ESI. $\dagger$ CsAc-1 exhibits $10 \%$ enhanced lifetime of $1.4 \mu$ s compared to $\tau_{\text {ave }}$ of CsAc- 0 due to longer $\tau_{2}$ slow decay time. The longer lifetime indicates the suppressed trap-assisted recombination and improved quality of the bulk perovskite.

Space charge limited current (SCLC) measurements were used to determine the trap density in the perovskite films. We prepared electron only devices, which have the $\mathrm{FTO} / \mathrm{SnO}_{2} /$ perovskite/PCBM/Au structure using CsAc-0 and CsAc-1. As seen in Fig. 4c and d, the dark current shows an ohmic response (linear increase dependent on the voltage) at lower voltage. The current shows nonlinear increases at certain voltage, where all traps are filled by injected carriers. That transition point is called the trap-filled limit voltage $\left(V_{\mathrm{TFL}}\right)$. We found the ohmic region and TFL region using linear fitting which has a slope of 1 up to 3 . From the cross-point of the fitted curve, we get the $V_{\mathrm{TFL}}$ of CsAc-0 and CsAc-1, corresponding to $0.605 \mathrm{~V}$ and $0.480 \mathrm{~V}$, respectively. The $V_{\mathrm{TFL}}$ point is linearly proportional to the trap density $\left(N_{\text {trap }}\right)$ by the equation $N_{\text {trap }}=$ $\left(2 \varepsilon \varepsilon_{0} \cdot V_{\mathrm{TFL}}\right) / q L^{2}$, where $\varepsilon$ is the dielectric constant, $\varepsilon_{0}$ is vacuum permittivity, $q$ is the charge of an electron, $L$ is the thickness of the film. We used an $\varepsilon$ value of 46.9 from the literature. ${ }^{60}$ Correspondingly, we found that the CsAc- 1 film has a lower trap density $\left(N_{\text {trap }}=3.9 \times 10^{15} \mathrm{~cm}^{-3}\right)$ than the CsAc-0 film $\left(N_{\text {trap }}=4.9 \times 10^{15} \mathrm{~cm}^{-3}\right)$. 
We tested the thermal stability of CsAc-1 perovskite using temperature controlled in situ UV-Vis spectroscopy. For the thermal stability test, we put the sample, which has the glass/ FTO/CsAc-0 or CsAc-1 perovskite structure, on the thermoelectrically temperature-controlled Peltier element with a small window. A PDMS layer physically covered the perovskite surface to reduce interaction with moisture and oxide in ambient conditions. The incident light $(200 \mathrm{~nm}$ to $1100 \mathrm{~nm}$, low intensity) passes through the window in the Peltier element, glass/FTO, perovskite layer, PDSM and is collected by the detector (schematic of experiment set-up is in Fig. S13, ESI $\dagger$ ). The UV-vis spectra were collected every minute for 510 minutes. The temperature increased up to $120^{\circ} \mathrm{C}$ during $6 \mathrm{~min}$ and was kept at $120^{\circ} \mathrm{C}$ for $\sim 500$ minutes. Thereafter, the sample was cooled down to room-temperature spontaneously. In Fig. 4e and f, we display the initial 8 spectra (heating from $20^{\circ} \mathrm{C}$ to $120^{\circ} \mathrm{C}$ ) and the final 8 spectra (cooling down from $120^{\circ} \mathrm{C}$ to $28{ }^{\circ} \mathrm{C}$ ). Both perovskite samples showed stable absorbance spectra during the $\sim 500$ minutes at $120^{\circ} \mathrm{C}$. The extracted absorption onset is listed in Table S7, ESI $\dagger$ and more data in the visible range are depicted in Fig. S14, ESI. $\dagger$ The absorption onset of the CsAc-0 and CsAc- 1 blue shifted from $805.9 \mathrm{~nm}$ to $783.4 \mathrm{~nm}$ and from $808.4 \mathrm{~nm}$ to $782.8 \mathrm{~nm}$, respectively, while increasing temperature to $120^{\circ} \mathrm{C}$. We attribute this observation to a temperature dependent band gap shift of the perovskite layer due to thermal expansion of the crystal lattice, consistent to previous reports. ${ }^{61}$ The bandgap decreased by about $0.05 \mathrm{eV}$ by heating to $120^{\circ} \mathrm{C}$. CsAc- 1 shows a slightly narrower optical band gap compared to CsAc-0, correlated to the slight red-shift of CsAc-1 in steady-state PL analysis. After cooling the samples down to $28{ }^{\circ} \mathrm{C}$, we found that for CsAc-0 the absorption onset was shifted to a lower wavelength, and absorbance in the visible range is reduced, presumably due to thermal decomposition. Meanwhile, the absorbance spectra of CsAc-1 films are recovered to similar values of their initial absorbance spectrum. In Fig. S15, ESI, $\dagger$ we displayed the absorbance spectrum that clearly confirms the difference in absorbance before and after the thermal stress test. This points to a more stable perovskite film by CsAc doping, likely due to a decrease in defect sites and a reduced lattice strain.

\section{Conclusion}

We have demonstrated that the CsAc dopant is effective to reduce the hysteresis phenomenon and to improve the stability of $\mathrm{FAMAPbI}_{3}$ perovskite solar cells. The $\mathrm{Cs}^{+}$and $\mathrm{Ac}^{-}$ions are incorporated in the fabrication of sequential deposited perovskite layers using CsAc added $\mathrm{PbI}_{2}$ layer. The $\mathrm{Cs}^{+}$is incorporated in the final $\mathrm{FAMAPbI}_{3}$ perovskite, where it reduces lattice strain and improves stability and optoelectrical properties. The $\mathrm{Ac}^{-}$participates in the interaction between $\mathrm{PbI}_{2}-\mathrm{DMSO}$ intermediate phases and it promotes $\mathrm{Cs}^{+}$-settling in the perovskite layer. The successfully incorporated $\mathrm{Cs}^{+}$through the CsAc added $\mathrm{PbI}_{2}$ layer gives a slight improvement of the PCE in per- ovskite solar cells and a significant improvement of stability, due to lowered trap density in the bulk perovskite, longer carrier recombination lifetimes and improved strain relaxation under illumination and under thermal stress. We anticipate that the precise investigation of the role of various dopant ions will bring further improvement of perovskite solar cells.

\section{Experimental section}

\section{Materials}

All the chemical regents are commercially available and used without further purification. All solvents, 4-tert-butylpyridine, bis(trifluoromethylsulfonyl) imide lithium salt (Li-FTSI) were purchased from Sigma-Aldrich. Formamidinium iodide (FAI), methylammonium iodide (MAI), tris(2-(1H-pyrazol-1-yl)4-tert-butylpyridine)-cobalt(III) tris(bis-(trifluoromethylsulfonyl) imide) (FK209) were purchased from GreatCell Solar, and methylammonium chloride (MACl) was purchased from Dyenamo. The $\mathrm{SnO}_{2}$ Colloidal solution $\left(\mathrm{SnO}_{2}, 15 \%\right.$ in $\left.\mathrm{H}_{2} \mathrm{O}\right)$ was obtained from Alfa Aesar. The hole transport material 2,2',7,7'-tetrakis-9,9'-spirobifluorene (spiro-OMeTAD), was purchased from Borun.

\section{Solution preparation}

Perovskite precursor. The $1.5 \mathrm{M}$ of $\mathrm{PbI}_{2}$ containing $0,1,2$ and $3 \mathrm{~mol} \%$ of CsAc was dissolved in a mixture of DMF and DMSO (9:1 volume ratio) and then stirred at $70{ }^{\circ} \mathrm{C}$ overnight in an Ar glove box. For the mixed halide solution, $90 \mathrm{mg}$ of FAI, $6.5 \mathrm{mg}$ of MAI, and $9 \mathrm{mg}$ of MACl mixed in $1 \mathrm{ml}$ isopropanol solution and was stirred at RT for 1 hour.

Doped spiro-MeOTAD solution. The solution of $70 \mathrm{mM}$ spiro-MeOTAD in chlorobenzene was prepared with additives of Li-TFSI, FK209, tBP. The final molar ratio of additives was $0.53,0.03$, and 3.26 for Li-TFSI, FK209 and tBP, respectively.

\section{Device fabrication}

The glass/etched fluorine doped tin oxide (FTO)-glass substrate was cleaned sequentially using detergent, acetone, ethanol, and deionized water in an ultrasonic bath for $30 \mathrm{~min}$, respectively. The diluted $\mathrm{SnO}_{2}$ (volume rate of $15 \% \mathrm{SnO}_{2}$ colloidal in $\mathrm{H}_{2} \mathrm{O}: \mathrm{H}_{2} \mathrm{O}=1: 4$ ) was spin coated onto glass/FTO substrate at $3000 \mathrm{rpm}$ for $30 \mathrm{~s}$, and then annealed in ambient air at $150{ }^{\circ} \mathrm{C}$ for $30 \mathrm{~min}$, the perovskite layer was deposited using a sequential deposition method in a $\mathrm{N}_{2}$ glove box. The prepared $\mathrm{PbI}_{2}$ solution was coated on the $\mathrm{SnO}_{2}$ layer at $1500 \mathrm{rpm}$ for $20 \mathrm{~s}$ and $5000 \mathrm{rpm}$ for $30 \mathrm{~s}$, and annealed for $1 \mathrm{~min}$ at $70{ }^{\circ} \mathrm{C}$. After $\mathrm{PbI}_{2}$ had cooled down to RT, a mixed cation halide solution was spin coated on the $\mathrm{PbI}_{2}$ layer at $1900 \mathrm{rpm}$ for $30 \mathrm{~s}$. After finishing the spin coating, the reddish-brown colored film was exposed to ambient air and annealed at $145{ }^{\circ} \mathrm{C}$ for $25 \mathrm{~min}$. After annealing, the black phase perovskite film was brought back to the $\mathrm{N}_{2}$ glove box. The prepared spiro-OMeTAD solution was coated at $4000 \mathrm{rpm}$ for $30 \mathrm{~s}$ using dynamic spin casting. Finally, $80 \mathrm{~nm}$ of Au electrodes were deposited by thermal evaporation. The electrode area was $4 \mathrm{~mm} \times 5 \mathrm{~mm}$. 


\section{Characterization}

The photovoltaic characteristics were measured using an LED solar simulator (Wave Labs SINUS-70 with UV and IR range extenders). Light intensity (10-100 $\mathrm{mW} \mathrm{cm}^{-2}$ ) was controlled by an auto calibration system. The $J-V$ data were measured with a scan rate of $100 \mathrm{mV} \mathrm{s}^{-1}$ and it was recorded with a Xtralien X200 (Ossila) source meter. The active area was defined by a metal mask with a circular aperture of $0.125 \mathrm{~cm}^{2}$. For maximum power point tracking, we scanned the $J V$ curve under 1.5 AM simulated sunlight in ambient air and applied maximum power voltage until the next measurement. External quantum efficiency (EQE) spectra were measured on a labmade setup consisting of a xenon lamp (ASB-XE-175), a monochromator (Spectral Products, CM110), and a Labjack U6 DAQ board. The setup was calibrated with a certified silicon solar cell (Fraunhofer ISE). X-ray diffraction (XRD) was performed with a Siemens D5000 $\theta-2 \theta$ goniometer with $\mathrm{Cu} \mathrm{K} \alpha(\lambda=$ $1.54051 \AA$ A). Scanning electron microscopy (SEM) pictures were taken using the Zeiss LEO 1530/1550 microscope. A Bruker Vertex 70v Fourier transform infrared (FTIR) spectrometer was used to record the IR spectra. X-ray photoelectron spectra (XPS) were recorded using the instrument PHI Quantera II (Physical Electronics). Steady-state and time-resolved photoluminescence was observed with a fluorescence lifetime spectrometer (Quantaurus-Tau C11367-12, HAMAMATSU) using a $464 \mathrm{~nm}$ laser (PLP-10, HAMAMATSU, peak power of $231 \mathrm{~mW}$ and pulse duration of $53 \mathrm{ps}$ pulsed at a repetition rate of $2 \mathrm{MHz}$ ) for photoexcitation. The absorbance of the perovskite layer was measured in situ using a UV-Vis spectroscopy set-up with Ocean Optics QE6500 spectrometer and DH-2000BAL light source. For the thermal stress test, the temperature was controlled by a TMS-93 Stage Temp Controller (Linkam), and absorbance data $(200<\lambda<1200 \mathrm{~nm})$ was recorded using the Ocean Optics OceanView software every 1 minute for 510 minutes.

\section{Conflicts of interest}

There are no conflicts to declare.

\section{Acknowledgements}

This work was supported by the National Research Foundation of Korea Grant funded by the Korean Government (NRF-2020R1A6A3A03039130), the Swedish Energy Agency (43294-1) and the STandUP for Energy program.

\section{References}

1 S. D. Stranks, G. E. Eperon, G. Grancini, C. Menelaou, J. Marcelo, M. J. Alcocer, T. Leijtens, L. M. Herz, A. Petrozza and H. J. Snaith, Science, 2013, 342, 341-344.
2 S. De Wolf, J. Holovsky, S. J. Moon, P. Loper, B. Niesen, M. Ledinsky, F. J. Haug, J. H. Yum and C. Ballif, J. Phys. Chem. Lett., 2014, 5, 1035-1039.

3 M. Saliba, J. P. Correa-Baena, M. Gratzel, A. Hagfeldt and A. Abate, Angew. Chem., Int. Ed., 2018, 57, 2554-2569.

4 M. Baranowski and P. Plochocka, Adv. Energy Mater., 2020, 10, 1903659.

5 W. S. Yang, J. H. Noh, N. J. Jeon, Y. C. Kim, S. Ryu, J. Seo and S. I. Seok, Science, 2015, 348, 1234-1237.

6 J. Burschka, N. Pellet, S. J. Moon, R. Humphry-Baker, P. Gao, M. K. Nazeeruddin and M. Gratzel, Nature, 2013, 499, 316-319.

7 U. Amita and G. Michael, Sci. Adv., 2018, 4, e1701402.

8 M. Li, X. Yan, Z. Kang, X. Liao, Y. Li, X. Zheng, P. Lin, J. Meng and Y. Zhang, ACS Appl. Mater. Interfaces, 2017, 9, 7224-7231.

9 B. Yang, J. Keum, O. S. Ovchinnikova, A. Belianinov, S. Chen, M. H. Du, I. N. Ivanov, C. M. Rouleau, D. B. Geohegan and K. Xiao, J. Am. Chem. Soc., 2016, 138, 5028-5035.

10 B. Saparov and D. B. Mitzi, Chem. Rev., 2016, 116, 45584596.

11 T. M. Brenner, Y. Rakita, Y. Orr, E. Klein, I. Feldman, M. Elbaum, D. Cahen and G. Hodes, Chem. Mater., 2016, 28, 6501-6510.

12 F. Meillaud, A. Shah, C. Droz, E. Vallat-Sauvain and C. Miazza, Sol. Energy Mater. Sol. Cells, 2006, 90, 29522959.

13 G. Han, H. D. Hadi, A. Bruno, S. A. Kulkarni, T. M. Koh, L. H. Wong, C. Soci, N. Mathews, S. Zhang and S. G. Mhaisalkar, J. Phys. Chem. C, 2018, 122, 13884-13893.

14 Z. Wang, Y. Zhou, S. Pang, Z. Xiao, J. Zhang, W. Chai, H. Xu, Z. Liu, N. P. Padture and G. Cui, Chem. Mater., 2015, 27, 7149-7155.

15 C. C. Stoumpos, C. D. Malliakas and M. G. Kanatzidis, Inorg. Chem., 2013, 52, 9019-9038.

16 K. N. Liang, D. B. Mitzi and M. T. Prikas, Chem. Mater., 1998, 10, 403-411.

17 K. Hwang, Y. S. Jung, Y. J. Heo, F. H. Scholes, S. E. Watkins, J. Subbiah, D. J. Jones, D. Y. Kim and D. Vak, Adv. Mater., 2015, 27, 1241-1247.

18 T. Liu, Q. Hu, J. Wu, K. Chen, L. Zhao, F. Liu, C. Wang, H. Lu, S. Jia, T. Russell, R. Zhu and Q. Gong, Adv. Energy Mater., 2016, 6, 1501890.

19 D. Liu, M. K. Gangishetty and T. L. Kelly, J. Mater. Chem. A, 2014, 2, 19873-19881.

20 X. Cao, L. Zhi, Y. Li, F. Fang, X. Cui, Y. Yao, L. Ci, K. Ding and J. Wei, J. Mater. Chem. C, 2017, 5, 7458-7464.

21 H. Zhang, J. Mao, H. He, D. Zhang, H. L. Zhu, F. Xie, K. S. Wong, M. Grätzel and W. C. H. Choy, Adv. Energy Mater., 2015, 5, 1501354.

22 B. Li, J. Shi, J. Lu, W. L. Tan, W. Yin, J. Sun, L. Jiang, R. T. Jones, P. Pigram, C. R. McNeill, Y.-B. Cheng and J. J. Jasieniak, ACS Appl. Energy Mater., 2020, 3, 3358-3368.

23 S. Li, H. Ren and Y. Yan, Appl. Surf. Sci., 2019, 484, 11911197. 
24 O. A. Syzgantseva, M. Saliba, M. Gratzel and U. Rothlisberger, J. Phys. Chem. Lett., 2017, 8, 1191-1196.

25 L. Zhang, W. Cui, Z. Zang, F. Tian, X. Li and G. Qin, Sol. Energy, 2019, 188, 224-229.

26 Y. H. Park, I. Jeong, S. Bae, H. J. Son, P. Lee, J. Lee, C.-H. Lee and M. J. Ko, Adv. Funct. Mater., 2017, 27, 1605988.

27 G. Zhou, J. Wu, Y. Zhao, Y. Li, J. Shi, Y. Li, H. Wu, D. Li, Y. Luo and Q. Meng, ACS Appl. Mater. Interfaces, 2018, 10, 9503-9513.

28 J. Huang, P. Xu, J. Liu and X. Z. You, Small, 2017, 13, 1603225.

29 Q. Li, Y. Zhao, R. Fu, W. Zhou, Y. Zhao, X. Liu, D. Yu and Q. Zhao, Adv. Mater., 2018, e1803095, DOI: 10.1002/ adma.201803095.

30 X. Yi, Z. Zhang, A. Chang, Y. Mao, Y. Luan, T. Lin, Y. Wei, Y. Zhang, F. Wang, S. Cao, C. Li and J. Wang, Adv. Energy Mater., 2019, 9, 1901726.

31 T. Liu, H. Lai, X. Wan, X. Zhang, Y. Liu and Y. Chen, Chem. Mater., 2018, 30, 5264-5271.

32 R. E. Beal, D. J. Slotcavage, T. Leijtens, A. R. Bowring, R. A. Belisle, W. H. Nguyen, G. F. Burkhard, E. T. Hoke and M. D. McGehee, J. Phys. Chem. Lett., 2016, 7, 746-751.

33 G. E. Eperon, G. M. Paternò, R. J. Sutton, A. Zampetti, A. A. Haghighirad, F. Cacialli and H. J. Snaith, J. Mater. Chem. A, 2015, 3, 19688-19695.

34 S. Yuan, Y. Cai, S. Yang, H. Zhao, F. Qian, Y. Han, J. Sun, Z. Liu and S. Liu, Sol. RRL, 2019, 3, 1900220.

35 J. Du, S. Liu, J. Wu, W. Zhang, W. Zhang, A. Mei, Y. Rong, Y. Hu and H. Han, Sol. RRL, 2020, 4, 2000455.

36 C. Gao, H. Dong, X. Bao, Y. Zhang, A. Saparbaev, L. Yu, S. Wen, R. Yang and L. Dong, J. Mater. Chem. C, 2018, 6, 8234-8241.

37 L. Chao, Y. Xia, B. Li, G. Xing, Y. Chen and W. Huang, Chem, 2019, 5, 995-1006.

38 M. Deepa, M. Salado, L. Calio, S. Kazim, S. M. Shivaprasad and S. Ahmad, Phys. Chem. Chem. Phys., 2017, 19, 40694077.

39 M.-C. Tang, Y. Fan, D. Barrit, R. Li, H. X. Dang, S. Zhang, T. J. Magnanelli, N. V. Nguyen, E. J. Heilweil, C. A. Hacker, D.-M. Smilgies, K. Zhao, A. Amassian and T. D. Anthopoulos, Sol. RRL, 2020, 4, 2000272.

40 M. Saliba and L. Etgar, ACS Energy Lett., 2020, 5, 2886-2888.

41 W. Nie, J. C. Blancon, A. J. Neukirch, K. Appavoo, H. Tsai, M. Chhowalla, M. A. Alam, M. Y. Sfeir, C. Katan, J. Even, S. Tretiak, J. J. Crochet, G. Gupta and A. D. Mohite, Nat. Commun., 2016, 7, 11574.

42 K. Domanski, B. Roose, T. Matsui, M. Saliba, S.-H. TurrenCruz, J.-P. Correa-Baena, C. R. Carmona, G. Richardson, J. M. Foster, F. De Angelis, J. M. Ball, A. Petrozza, N. Mine, M. K. Nazeeruddin, W. Tress, M. Grätzel, U. Steiner, A. Hagfeldt and A. Abate, Energy Environ. Sci., 2017, 10, 604-613.
43 M. V. Khenkin, K. M. Anoop, I. Visoly-Fisher, S. Kolusheva, Y. Galagan, F. Di Giacomo, O. Vukovic, B. R. Patil, G. Sherafatipour, V. Turkovic, H.-G. Rubahn, M. Madsen, A. V. Mazanik and E. A. Katz, ACS Appl. Energy Mater., 2018, 1, 799-806.

44 J. Lee and S. Baik, RSC Adv., 2018, 8, 1005-1013.

45 K. Zhang, Z. Wang, G. Wang, J. Wang, Y. Li, W. Qian, S. Zheng, S. Xiao and S. Yang, Nat. Commun., 2020, 11, 1006.

46 N. Ahn, D. Y. Son, I. H. Jang, S. M. Kang, M. Choi and N. G. Park, J. Am. Chem. Soc., 2015, 137, 8696-8699.

47 L. Shu, A. R. Condrate, Sr., D. S. Jang and M. R. Spriggs, J. Mater. Sci., 1989, 24, 3873-3877.

48 C. W. Lai, F. W. Low, M. F. Tai and S. B. Abdul Hamid, Adv. Polym. Technol., 2018, 37, 1712-1721.

49 J. F. Moulder, W. F. Stickle, P. E. Sobol and K. D. Bomben, Handbook of $x$-ray photoelectron spectroscopy: a reference book of standard spectra for identification and interpretation of XPS data, Physical Electronics Division, Perkin-Elmer Corp., Eden Prairie, Minn, 1992.

50 J. D. McGettrick, K. Hooper, A. Pockett, J. Baker, J. Troughton, M. Carnie and T. Watson, Mater. Lett., 2019, 251, 98-101.

51 Q. Chen, H. Zhou, T. B. Song, S. Luo, Z. Hong, H. S. Duan, L. Dou, Y. Liu and Y. Yang, Nano Lett., 2014, 14, 4158-4163.

52 X. Zheng, C. Wu, S. K. Jha, Z. Li, K. Zhu and S. Priya, ACS Energy Lett., 2016, 1, 1014-1020.

53 W. Jian, R. Jia, H.-X. Zhang and F.-Q. Bai, Inorg. Chem. Front., 2020, 7, 1741-1749.

54 S. Tao, I. Schmidt, G. Brocks, J. Jiang, I. Tranca, K. Meerholz and S. Olthof, Nat. Commun., 2019, 10, 2560.

55 S. X. Tao, X. Cao and P. A. Bobbert, Sci. Rep., 2017, 7, 14386.

56 R. Prasanna, A. Gold-Parker, T. Leijtens, B. Conings, A. Babayigit, H. G. Boyen, M. F. Toney and M. D. McGehee, J. Am. Chem. Soc., 2017, 139, 11117-11124.

57 P. Calado, D. Burkitt, J. Yao, J. Troughton, T. M. Watson, M. J. Carnie, A. M. Telford, B. C. O'Regan, J. Nelson and P. R. F. Barnes, Phys. Rev. Appl., 2019, 11, 044005.

58 D.-Y. Son, J.-W. Lee, Y. J. Choi, I.-H. Jang, S. Lee, P. J. Yoo, H. Shin, N. Ahn, M. Choi, D. Kim and N.-G. Park, Nat. Energy, 2016, 1, 16081.

59 D. Shi, V. Adinolfi, R. Comin, M. Yuan, E. Alarousu, A. Buin, Y. Chen, S. Hoogland, A. Rothenberger, K. Katsiev, Y. Losovyj, X. Zhang, P. A. Dowben, O. F. Mohammed, E. H. Sargent and O. M. Bakr, Science, 2015, 347, 519-522.

60 Y. Huang, L. Li, Z. Liu, H. Jiao, Y. He, X. Wang, R. Zhu, D. Wang, J. Sun, Q. Chen and H. Zhou, J. Mater. Chem. A, 2017, 5, 8537-8544.

61 M. Tan, B. Chen, Y. Zhang, M. Ni, W. Wang, H. Zhang, Q. Zhou, Y. Bao and Y. Wang, J. Phys. Chem. C, 2020, 124, 5093-5098. 